Journal of Educational

Technology \& Online Learning

Volume 4 | Issue 2 |2021

http://dergipark.org.tr/jetol

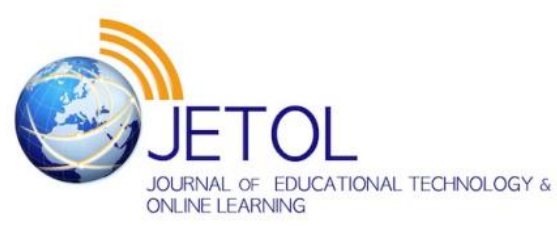

\title{
A comparative examination of social perception, network structure, important nodes, and discourses regarding ASD awareness over online networks: A social network and content analysis
}

\author{
Sunagül Sani-Bozkurt ${ }^{\text {a* (D) }}$ \\ ${ }^{a}$ Anadolu University, Turkey.
}

Suggested citation: Sani-Bozkurt, S. (2021). A comparative examination of social perception, network structure, important nodes, and discourses regarding ASD awareness over online networks: A social network and content analysis. Journal of Educational Technology \& Online Learning, 4(2), 293-309.

\begin{tabular}{l} 
Article Info \\
\hline Keywords: \\
Autism spectrum disorder \\
Awareness \\
Online social networks \\
Social network analysis \\
Content analysis
\end{tabular}

Research Article

\begin{abstract}
The purpose of this research is to examine activities carried out on Twitter, which is a social media platform, on April 2 Autism Awareness Day; network structure in Turkey and in a global context, interaction patterns, the important nodes, user profiles, hashtag usage, and social mode within the context of the Twitter messages and discourses. In the research, mixed research method was adopted, and social network analysis and content analysis methods were used. The sample constitutes a total of 16565 people with 2790 people from Turkey and 13775 people from all over the world. According to the findings in the sample and Turkey as well as the global clustered-community group structures has been observed that the structure of the network. When compared with global examples of effective institutions related to the ASD in Turkey in the global context, the process of institutions and corporate entities has been determined to be more effective. It is seen that especially famous people who are known in the global context are involved in the process in order to reach more audiences. It is found that hashtag use in Turkey is limited, for example, on the other hand, in a global context hashtag use is more diverse to reach different target groups Comparative concept maps revealed that fewer themes were issued in Turkey while there was a wide range of themes in the global context. Social mode is positive in both samples.
\end{abstract}

\section{Introduction}

Autism spectrum disorder (ASD) is a heterogenous and neuro-developmental disorder characterized by repetitive and obsessive behaviors, interests, and activities limited to deficiencies in social interaction and communication (APA, 2013). ASD is encountered in all races and ethnic groups, briefly in different geographies and societies, and its prevalence is increasing every day (Elsabbagh et al., 2012; Maenner et al., 2020). According to the latest data published by the Centers for Disease Control and Prevention (CDC) (2020), one out of every 54 children is diagnosed with ASD. In addition to genetic factors such as the incidence of ASD four times higher in boys than girls and the higher risk in monozygotic twins compared to dizygotic twins (Bourgeron, 2016; Huguet et al., 2013; Ronald \& Hoekstra, 2011), environmental factors such as infections during pregnancy, especially advanced father's age, and neurochemical disorders in the blood-body fluids are also thought to possibly play a role in the emergence of this disorder (Korkmaz, 2010; Lord \& Bishop 2015).

\footnotetext{
* Corresponding author. Faculty of Education, Special Education Department, Anadolu University, Turkey. e-mail adress: ssbozkurt@ anadolu.edu.tr
} 


\section{Literature}

Since the causes of ASD are not known exactly, it is also not possible to take precautions before delivery for now. The earliest symptoms of ASD emerge with the absence of eye contact or avoiding eye contact, deficiency of social smiling, delay in language development and obsessive stereotypical behaviours in the first years of life. The severity of these symptoms may vary from slight to severe. Although it is predicted that a diagnosis can be made between the 18th and 24th months and earlier (Johnson \& Myers, 2007), many children with ASD are suggested to be diagnosed at the age of 4 and later (Maenner et al., 2020; Noterdaeme \& Hutzelmeyer-Nickels, 2010). There can be delays in early diagnosis due to the fact that descriptive behavioural characteristics of ASD may exhibit symptoms at the age of about 24 months or later (Guthrie et al., 2013; Ozonoff et al., 2010), families are not aware of the symptoms emerging in the early period or do not accept these symptoms/differences or difficulties are experienced during the diagnosis (Pisula, 2011). However, noticing ASD symptoms in the early period and early diagnosis is of critical importance in terms of planning the early education (Landa \& Kalb, 2012). Early diagnosis and the planning of education first depend on the knowledge and awareness of parents, caregivers, and relevant people, who are the primary people responsible for taking care of the child, regarding ASD (Wang et al., 2012). However, raising the awareness of only parents and people in the immediate environment is not an adequate effort for the child to maintain these acquired skills in society as an independent individual, shortly, to integrate into society.

When the situation resulting from the lack of knowledge and perception about ASD in society is combined with the concerns, anxiety, and stress of parents whose children have been diagnosed with ASD (Bitsika \& Sharpley, 2004; Kinnear et al., 2016), children with ASD and their parents face social isolation and exclusion and feel helpless (Al-Farsi et al., 2016; Bitsika \& Sharpley, 2004). It is assumed that the efforts to enhance the understanding and acceptance of a child's ASD-related behaviours by society can reduce both the labelling faced by parents and the difficulties they may have in raising a child with ASD (Kinnear et al., 2016). In this respect, considering ASD as a social communication disorder concerning society, the raising of social awareness is extremely significant for early diagnosis, early intervention, and integration into society.

Due to the increase in the incidence of ASD, ASD awareness is more crucial than ever. In line with this significance, the United Nations declared April as the Autism Awareness Month and April 2 as the Autism Awareness Day worldwide to raise social awareness of ASD. In this sense, awareness activities for ASD communities have become the focal point of some large international institutions and organizations (e.g., Autism Awareness, Autism Speaks-Light It Up Blue campaign, etc.) (Dillenburger et al., 2017). In this context, the awareness activities carried out throughout April aim to support individuals with ASD and their families worldwide, raise the awareness of the other part of the society of ASD in detail, promote early diagnosis and treatment, strengthen cooperation between institutions, and encourage scientific research on ASD. To this end, a limited number of scientific studies on ASD awareness were reached when the literature was reviewed (Alsehemi et al., 2017; Biber et al., 2018; Chansa-Kabali et al., 2019; Özçelik et al., 2015; Rakap et al., 2016). For example, in the study conducted by Alsehemi et al. (2017) and aiming to determine the ASD awareness level of society, more than half of the society was found to have poor knowledge about ASD. In the same study, ASD awareness was observed to be at a higher level in women compared to men; participants above the age of 30 had more knowledge than young participants. On the other hand, it was stated that inaccurate knowledge or misunderstanding was not associated with social status, education, or profession. However, it is recommended to generalize the results of this study to different societies. In the study carried out by Biber et al. (2018), it was aimed to raise awareness in mothers who had children aged between 4-6 but had no individuals with ASD in the family or among the first-degree relatives through the ASD education received and peer chats. According to the survey data, 25\% of the participant mothers stated that they had been aware of ASD before the education, whereas, due to the information acquired after the education, they asserted that their social awareness was much lower than they had assumed. The study 
results indicate that the study group has inaccurate knowledge, belief, and attitude about ASD, and due to these deficiencies, society behaves discriminatorily. The study performed by Chansa-Kabali et al. (2019) aimed to examine the knowledge and awareness of 488 pre-service teachers on ASD. To this end, considering the participants' responses to the survey questions, $79 \%$ said that they had never heard of ASD before the survey. While most of the participants expressed that they first learned about "autism" or "autism spectrum disorders" on TV (41\%), 61.9\% said they had no relevant experience in real life when asked about their ASD experiences. In line with this result, a higher need is suggested for activities related to ASD awareness. In addition to the general social awareness, in the study in which Özçelik et al. (2015) examined the knowledge and attitudes of 270 pediatricians, it was reported that participants had difficulty making a diagnosis using the autism criteria and comprehensive evaluation techniques used to diagnose children. Another study, conducted by Rakap et al. (2016), investigated the opinions of 504 pre-service teachers, who were registered in four different teaching programs, including the special education teaching program, and studying in the final year in five universities of Turkey, regarding teacher training programs on ASD. According to the responses obtained via the survey, the participants were found to have incomplete or inaccurate knowledge about the causes and characteristics of ASD. Based on these findings, it is recommended in the research that seminars related to pre-service and in-service training programs should be held, considering that adequate information about ASD cannot be obtained from teacher training programs.

When the relevant studies are summarized, the lack of knowledge about ASD comes to the fore as the common result, and data are collected from certain segments of society, such as families, doctors, and preservice teachers, via survey. At this point, it is assumed that there is a need for studies investigating the perspective of all segments of society with respect to ASD awareness using detailed analyses such as content/thematic analysis, discourse analysis, or social network analysis. With this perspective, it is extremely important to take into account the widespread impact, i.e., achievability of social awareness on ASD. In the activities of the 21 st-century technological era, especially the use of social media such as Twitter is unquestionably powerful (Pelletier et al., 2021). However, during the review of the scientific studies in the literature, no studies investigating ASD awareness over social media/social network structure were encountered, which is remarkable (Dillenburger et al., 2017). When social media platforms such as Twitter are considered as an important source of information storage that can be used to evaluate ASD awareness worldwide, the whole world shares information and encourages each other for their tendencies regarding education, health, social rights and future assurance of these individuals on the ASD Awareness Day within the social communication network. Thus, the viewpoint of the society can be revealed by performing social network analysis on social media from a broader perspective and addressing posts, e.g., tags, discourses, and interaction patterns, in terms of ASD awareness. Based on the reasons and significance mentioned above in line with these ideas, the general purpose of this study is to examine the activities carried out on Twitter on April 2, the World Autism Awareness Day, in Turkey and globally. Within the scope of this general research purpose, answers were sought to the research questions below:

On the World Autism Awareness Day,

- What are the network structure and interaction pattern?

- Who constitutes the important nodes, and what kind of user-profiles come to the fore?

- What kind of tags are used?

- What is the content of the social mood, messages, and discourses? 


\section{Methodology}

\subsection{Research Model/Design}

The convergent parallel design, one of the mixed research designs, was used in this study (Creswell, 2012). At the first stage of the study, the social network analysis method was used. In this analysis, quantitative and qualitative data are collected and analyzed together to determine the network structure and the information flow in the network. The social network analysis is an approach used to analyze and map the organizational communal structures and to determine the key nodes (shareholders) and the links (interactions) between the nodes (Hansen et al., 2010). The basic difference of the social network analysis from similar methods is its concentration on the relationships between social beings, these relationship models and practices. The social network analysis focuses on the interaction of a social being or actors with other beings or actors and how this interaction forms a framework or structure instead of individual behaviours, attitudes, and beliefs. The focal point of the social network analysis is not the individual characteristics of network members but relationships between the actors in the network (Wasserman \& Galaskiewicz, 1994). At the second stage of the study, the content analysis was employed to find out the important hashtags (tags) in the network structure, which was included in the sample, and the tweets that stood out according to the link value within the network structure (Berelson, 1952).

\subsection{Sampling or Study Group}

The Turkish sample of this study is comprised of 2,790 individuals who tweeted on April 2, the Autism Awareness Day, on Twitter, which is a microblogging website, and 3,422 lines of interaction among these individuals. The Turkish sample has an error margin of 1.86 at a confidence interval of $99 \%$. The second, global sample consisted of a total of 13,775 individuals and 20,545 lines of interaction among these individuals. This sample has an error margin of $1.10 \%$ at a confidence interval of $99 \%$. Accordingly, the power of the findings in this study to represent the current situation can be said to be high (RaoSoft, 2020).

\subsection{Data Collection and Analysis}

The research data were collected from online networks using the NodeXL software and examined by the social network analysis method. The «betweenness centrality» metrics of the nodes in the data obtained were calculated. Advanced analysis methods were applied to determine the structure inside the network. The obtained sample was visualized with the Harel-Koren Fast Multiscale interface (Harel \& Koren, 2001) and the Clauset-Newman-Moore clustering (Clauset et al., 2004) algorithms. The users' tweets were examined via content analysis. In the content analysis, the Leximancer software was used to determine themes, and the themes were then visualized in the form of concept maps. Using direct quotations about the relevant themes, the sample statements were specified, and thus, the research findings were supported.

\section{Findings}

\subsection{The network structure and important nodes}

The sampled Turkish network structure consisted of 2,790 individuals, and the global network structure included 13,775 individuals. The individuals in the Turkish network posted 3,103 unique tweets, and 319 of these tweets were retweeted and propagated. In the global network structure, a total of 17,523 unique tweets were posted, and 3,022 of them were retweeted. The maximum geodesic distance between the nodes in the Turkish network is 25 , and the average geodesic distance is 7.36. In the global network, the maximum geodesic distance was calculated as 16, and the average geodesic distance was calculated as 5.006267. The threshold value of this metric is 6 . Hence, it is possible to say that the participants in both networks are disconnected. This is also confirmed by the modularity value, which indicates the disintegration of the network structure. In this aspect, the Turkish network structure and the global network structure were calculated as 0.803686 and 0.701466 , respectively. Although these values show similar results for both network structures, it is observed that the values taken by the global network structure are more positive, 
and the average geodesic distance is below the threshold value of 6 in this structure and above the threshold value of 6 in the Turkish network. The density value, which demonstrates the interaction in the network and varies between 0 and 1, was calculated as 0.000344287 for Turkey and 0.000154 for the global network. According to these data, the mutual interaction in the network can be said to be quite low. The information on the network metrics emerging on the ASD Awareness Day for Turkey and the global context is given in Table 1.

Table 1.

ASD awareness day network metrics

\begin{tabular}{lll}
\hline Network metrics & Turkey & Global \\
\hline Nodes & 2,790 & 13,775 \\
Unique interactions & 3,103 & 17,523 \\
Repetitive interactions & 319 & 3,022 \\
Total interaction & 3,422 & 20,545 \\
Self-cycle & 596 & 4,768 \\
Maximum geodesic distance & 25 & 16 \\
Average geodesic distance & 7.369726 & 5.006267 \\
Network density & 0.000344287 & 0.000154 \\
Modularity & 0.803686 & 0.701466 \\
\hline
\end{tabular}

Based on the numeric data obtained regarding the network structure, visuals defined as sociogram or network graphs were produced, and the network structure was analyzed. At this stage, the network graph subjected to no analysis was first obtained, and both networks about which data were collected were found to have a quite disorderly structure.
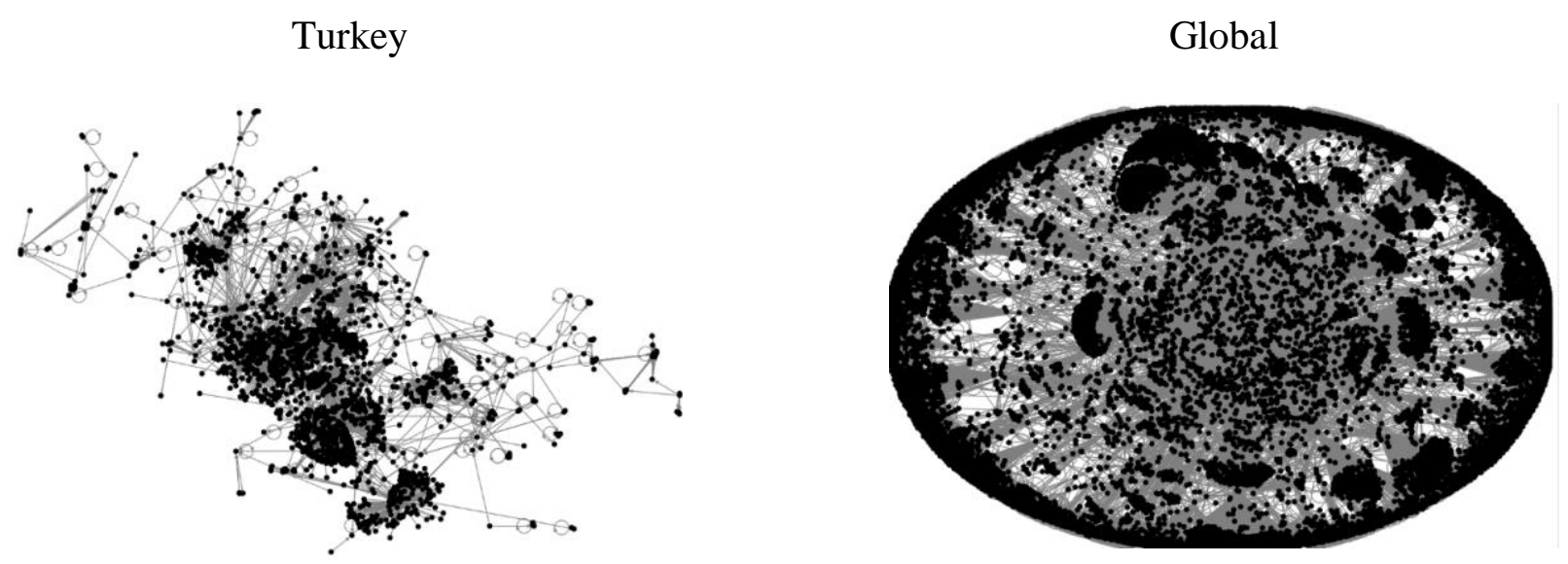

Figure 1. Raw view of the Twitter contents collected from Turkey and globally

For further analysis, advanced analysis methods were applied to determine the structure inside the network. The obtained sample was visualized with the Harel-Koren Fast Multiscale interface (Harel \& Koren, 2001) and the Clauset-Newman-Moore clustering (Clauset et al., 2004) algorithms. The obtained network structure was classified according to the six network structures explained by Smith et al. (2014). These network structures are briefly stated below.

- Divided-polarized crowds

- Unified-tight crowds

- Fragmented-brand clusters

- Clustered-community clusters

- In hub \& spoke-broadcast network

- Out hub \& spoke-support network 
Accordingly, the "Clustered-community clusters" network structure was observed to exist in both Turkish and global samples on the ASD Awareness Day. In this network structure, clusters are usually independent of each other and gather around the popular sources of information. It is an ineffective type of network in terms of the propagation of a thought, discourse, or idea (Smith et al., 2014). Thus, it can be said that an unorganized group exists on the ASD Awareness Day. This is considered as a situation, which also reduces the widespread impact of activities on online social networks on the ASD Awareness Day. At this point, the presence of an organized group regarding ASD awareness may affect information sharing between different disciplines. Taking into account that ASD is considered a complex and heterogeneous disorder, the interaction of many groups in educational fields such as special education and integration, health-related fields such as genetics, psychiatry and gastroenterology, and social-cultural field may enhance the power of awareness.

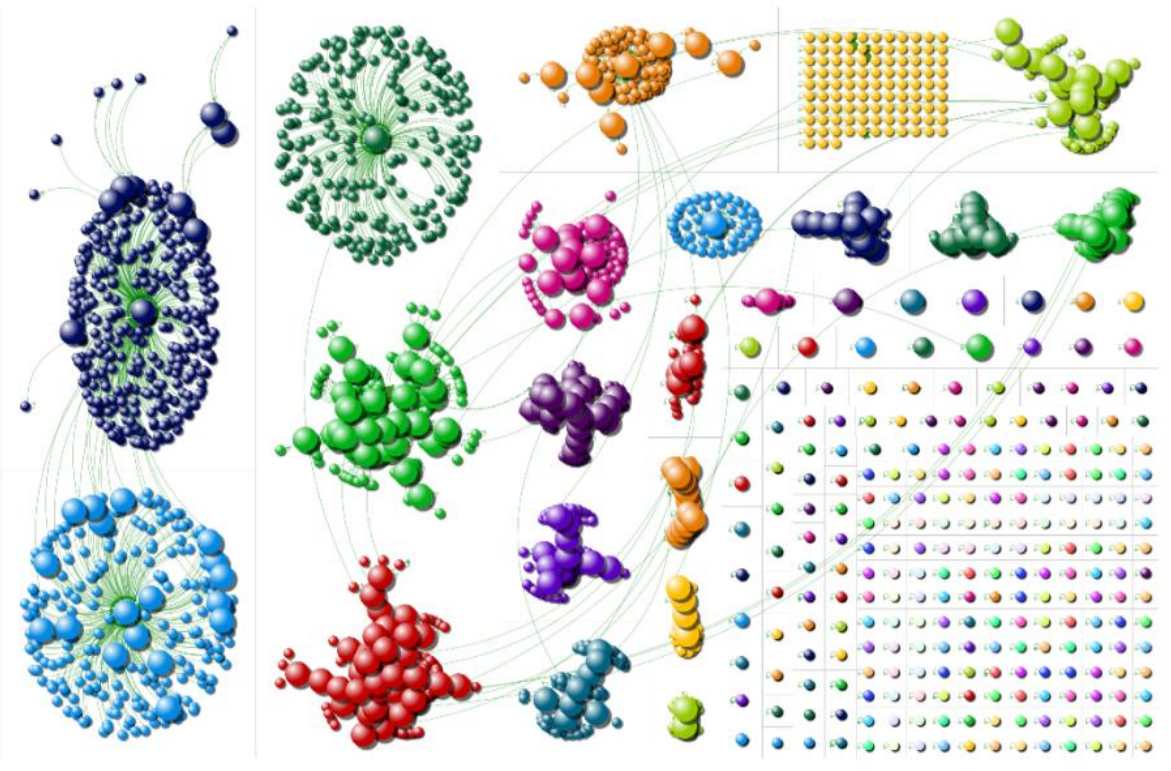

Figure 2. Turkish network structure

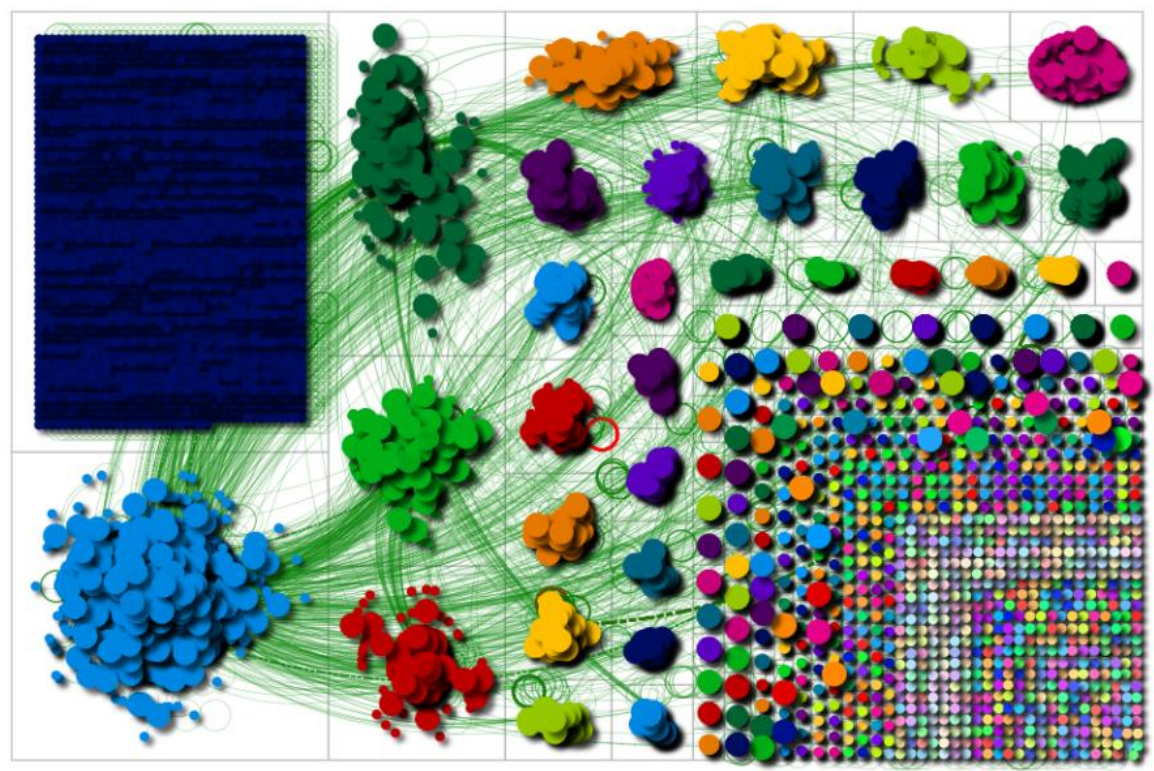

Figure 3. Global network structure

The striking point in the sociogram analysis (Figures 2 and 3 ) is that the nodes in the Turkish network and the interaction between the groups created by these nodes are highly sparse, and the nodes and the 
interaction between the groups created by the nodes are denser although such structuring is more difficult in the global aspect. Hence, it is thought that this limitation in Turkey results from the approach on the basis of a single society. Therefore, the node interactions can be sparser compared to the global network structure. Moreover, this difference seems insignificant when both network metrics are examined (Table 1).

\subsection{Influential User and Tag Analysis}

At this stage of the study, the betweenness centrality value was calculated for each participant to determine which nodes were more influential. Betweenness centrality shows to what extent a node is in direct connection with the nodes which are not directly connected (Gürsakal, 2009). In this context, betweenness centrality is an important metric indicating the power of nodes to connect the other nodes (Hansen et al., 2010). According to the data obtained, the first 20 nodes are presented in Table 2; the names in individual accounts are anonymized, and the corporate accounts are stated directly.

Table 2.

Betweenness centrality of influential users

\begin{tabular}{llll}
\hline Turkey & & Global & Betweenness Centrality \\
\hline Node & Betweenness Centrality & Node & 12343887.791 \\
\hline D1 & 9999.0 & autismspeaks & 5807978.028 \\
hergunyenibilgi & 9608.1 & D1 & 3947281.164 \\
D2 & 8439.0 & positanolimoser & 3568934.991 \\
kafiyelordu & 8335.3 & D2 & 3206274.656 \\
10ikincigezegen & 8090.3 & lagnnjsf & 3025913.662 \\
D3 & 8052.4 & luvwins2016 & 2607600.952 \\
D4 & 7731.8 & D3 & 2557960.734 \\
D5 & 7085.8 & D4 & 2393788.579 \\
psikiyatrider & 6252.0 & spandandiagnost & 2160223.078 \\
D6 & 6173.5 & nydailynews & 2061766.901 \\
D7 & 6118.7 & sachin_rt & 2047175.490 \\
D8 & 5079.5 & D5 & 1680102.127 \\
otizmemavi & 4235.1 & kerrymagro & 1557518.408 \\
D9 & 4170.7 & autismspeakscan & 1395880.877 \\
D10 & 3501.6 & D6 & 1371408.691 \\
D11 & 3381.9 & hollyrpeete & 1341738.043 \\
D12 & 3381.9 & rjszczerba & 1316724.087 \\
D13 & 3226.4 & mark_wahlberg & 1297834.826 \\
D14 & 3201.1 & tates5a & 1275239.881 \\
D15 & 2905.1 & asdmumgilly & \\
\hline
\end{tabular}

During the investigations on the Turkish sample, it was determined that 15 of the most influential 20 nodes were individual accounts, and 5 were corporate accounts or accounts which posted anonymously. Although only two accounts, @ailebakanligi and @ tohumotizm, stood out for their ASD-related activities, the corporate activities were not prominent enough inside the network. Considering the Turkish sample, it was found out that NGOs, which carried out activities on ASD, and private or official institutions, which were also involved in ASD-related activities, were not organized sufficiently on online social networks on the ASD Awareness Day.

Interesting results emerge when it comes to the global sample. Contrary to the rates of the Turkish sample, 6 individual accounts and 14 corporate accounts, along with the athletes, artists, scientists, etc., renowned in their countries, were found to participate in the activities held on the ASD Awareness Day. One of the most significant opportunities on Twitter is to use the power of fame of celebrities from different fields such as sports and art to raise awareness on ASD. It can be considered as a significant factor that the possibility of the tweets posted by celebrities on how to promote ASD awareness to be liked and retweeted is higher. @autismspeaks, the most influential user in the global sample, is an institution that is centered in 
New York, USA, and has adopted the dissemination of early diagnosis and treatment by raising awareness of ASD worldwide throughout April as a mission.

According to these analysis results, despite their ASD-awareness-related activities in different channels, institutions, directly or indirectly related to ASD, in the Turkish sample were found not to be active enough on online media. When the global activities are concerned, people who are liked and renowned and have followers in the society, as well as ASD-related institutions and organizations, are observed to participate in such activities. Following this analysis, the most preferred tags were reviewed and stated according to the frequency of their usage. Here, the remarkable point was the fact that the supporter clubs of the large football clubs were determined to carry out activities within the scope of social responsibility using the hashtags below. When the global sample is examined, it is observed that it was attempted to reach a larger mass using more hashtags, and the "mavi 1şık yak/light it up blue" slogan was emphasized more frequently compared to Turkey. The most used hashtags and their frequencies are given in Table 3.

Table 3.

The most used hashtags

\begin{tabular}{llll}
\hline The most used hashtags-Turkey & Frequency & The most used hashtags-Global & Frequency \\
\hline \#2nisanotizmfarkindalikgünü [April & 2 & & 17,532 \\
$\begin{array}{l}\text { AutismAwarenessDay] } \\
\text { \#otizmeksikdeğilfarkliolmaktır }\end{array}$ & 3,276 & \#worldautismawarenessday & \\
[autismisnotadisabilityitisadifference] & 483 & & 2,804 \\
\#otizm [autism] & 439 & \#lightitupblue & 853 \\
\#otizmemaviış1kyak [lightitupblueforautism] & 189 & \#autism & 530 \\
& & \#autismday2017 & 463 \\
& & \#unique & 401 \\
& & \#autismawarenessmonth & 336 \\
& & \#liub & 246 \\
\end{tabular}

\subsection{Social Mood and Discourse Analysis}

At the final stage of the study, it was tried to determine discourses in tweets, and relevant discourse examples were given. Then, the themes in these discourses were respectively presented in Figure 4 and Figure 5 with comparative concept maps. When the discourses were examined, it was revealed that individual tweets often adopted a manner of discourse oriented at raising awareness. In comparative concept maps, it is observed that fewer themes were approached in the activities in Turkey, and more themes were used in the global sense. In both samples, the social mood is positive. On the other hand, discourses in the form of slogans were preferred to change the social mood in the Turkish sample, whereas both slogan-type and informative discourses were used in the global sample. Some of these tweets in Turkey are briefly exemplified below.

- \#2NisanOtizmFarkındalıkGünü [April 2 Autism Awareness Day] it is important for anyone with a baby to know about autism in terms of early diagnosis.

- \#2NisanOtizmFarkındalıkGünü [April 2 Autism Awareness Day] Tell your child about autism so that your child can become a companion to a child with autism. So that your child can learn to accept and like what is different.

- AUTISM is not a Disability, it is a Difference!

- AUTISM is not a Disability, it is a Difference! We are aware of autism, we stand by people with autism. 
- Be aware of differences, light it up blue \#2NisanOtizmFarkındalıkGünü [April 2 Autism Awareness Day] \#otizmemaviış1kyak [light it up blue for autism] @tohumotizm

- 'Not Disabled. Different.'

- What is the Incidence of Autism? https://t.co/vPYzjvfPAQörülme+Sıklı̆g $1+$ Nedir + \#2NisanOtizmFarkındalıkGünü [April 2 Autism Awareness Day] @tohumotizm

- Happy Sunday! 疋 $\mathbb{R}$ 色 Today is \#2NisanOtizmFarkındalıkGünü [April 2 Autism Awareness Day]. To share life with love, \#otizmemaviışıkyak... [light it up blue for autism] $P$

- \#yakininolmasigerekmez [you don't have to have a relative with it] \#otizm [autism] \#2nisan [April 2] \#odfed [Federation of Autism Associations] \#otizmeylemplani [autism action plan]

- Because every child is special, and life is beautiful with awareness. \#2NisanOtizmFarkındalıkGünü [April 2 Autism Awareness Day]

- I wish awareness to all those who still haven't understood that autism is not a disability, it is a 'difference'. \#2NisanOtizmFarkındalıkGünü [April 2 Autism Awareness Day]

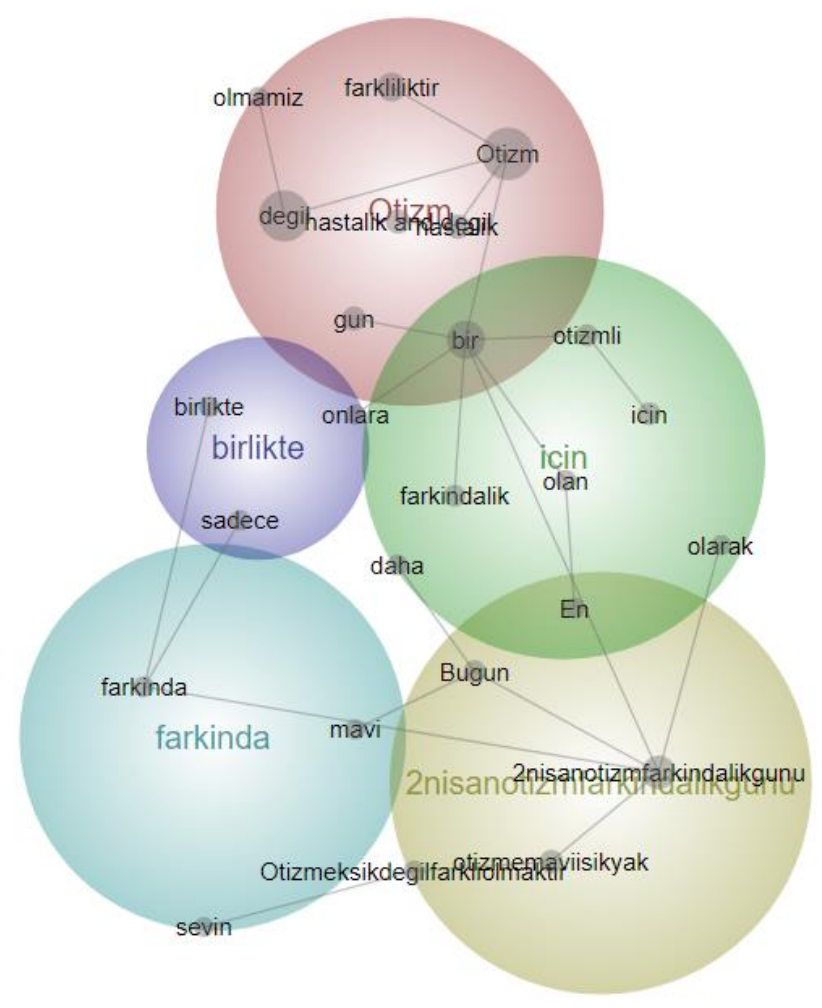

Figure 4. Tweets in Turkey

In the tweets posted for raising awareness, the topics of "difference" and "unique," "light it up blue," "love," and "acceptance" were mentioned. The informative tweets contained "a link shared about its incidence" and the topic of "autism action plan." In the tweets posted for raising awareness, the "Tohum Autism Foundation" was one of the prominent organizations which directly dealt with ASD. In the tweets posted in the global sample, the contents and discourses were aimed at raising awareness and informing.

- Hi friends!! Let's Light it up Blue for Autism Awareness \#WorldAutismAwarenessDay \#GlobalGoodEmiBlue

- Love to help spread awareness $\bigcirc$ @autismspeaks @autism \#GlobalGoodEmiBlue \#WorldAutismAwarenessDay

- \#WorldAutismAwarenessDay today + learn the facts about \#Autism this \#AutismAwarenessMonth Q 
- \#WorldAutismAwarenessDay Peers unconditionally accepting a classmate w/autism. Never leaving them on the sidelines alone $b / c$ they're different.

- \#WorldAutismAwarenessDay When you see an adult w/ autism acting out, showing compassion; understanding. \#Priceless

- \#WorldAutismAwarenessDay Having an autistic student in your NT class and saying to the mom "I'll do whatever it takes to make this work."

- \#WorldAutismAwarenessDay Making eye contact and interacting with my daughter even though she may appear not to notice or care. \#Priceless

- \#WorldAutismAwarenessDay Looking at my daughter with a knowing smile that says, "I see she's special \&amp; it's all good." \#Priceless

- Biomedical Autism Treatment Improves Eye Contact And Speech In Children https://t.co/0apVRGrFuD \#Nursing... https://t.co/z12wA2urwr

- We love featuring \#WorldAutismAwarenessDay DOCTORS in interviews. Please tell us about or @ mention your FAVORITE d... https://t.co/xSYnLdu6zm

- More than 3.5 million Americans live with an autism spectrum disorder. \#WorldAutismAwarenessDay

- Autism impacts the normal development of the brain in the areas of communication skills and cognitive function. \#WorldAutismAwarenessDay

- Autism spectrum disorder (ASD) \&amp; autism are general terms for a group of complex disorders of brain development. \#WorldAutismAwarenessDay

- Autism Myths: What You Think You Know Is Wrong https://t.co/BfJuBL5glY \#Nursing \#WorldAutismAwarenessDay https://t.co/T49HIEQKWi

- it's worth noting, as children, autism is supported but as adults ... pls hire my son-he needs a job to want to live \#WorldAutismAwarenessDay

- I could tell a complicated story about my brother's tragic, lonely life or I could just say "he was autistic" \#WorldAutismAwarenessDay

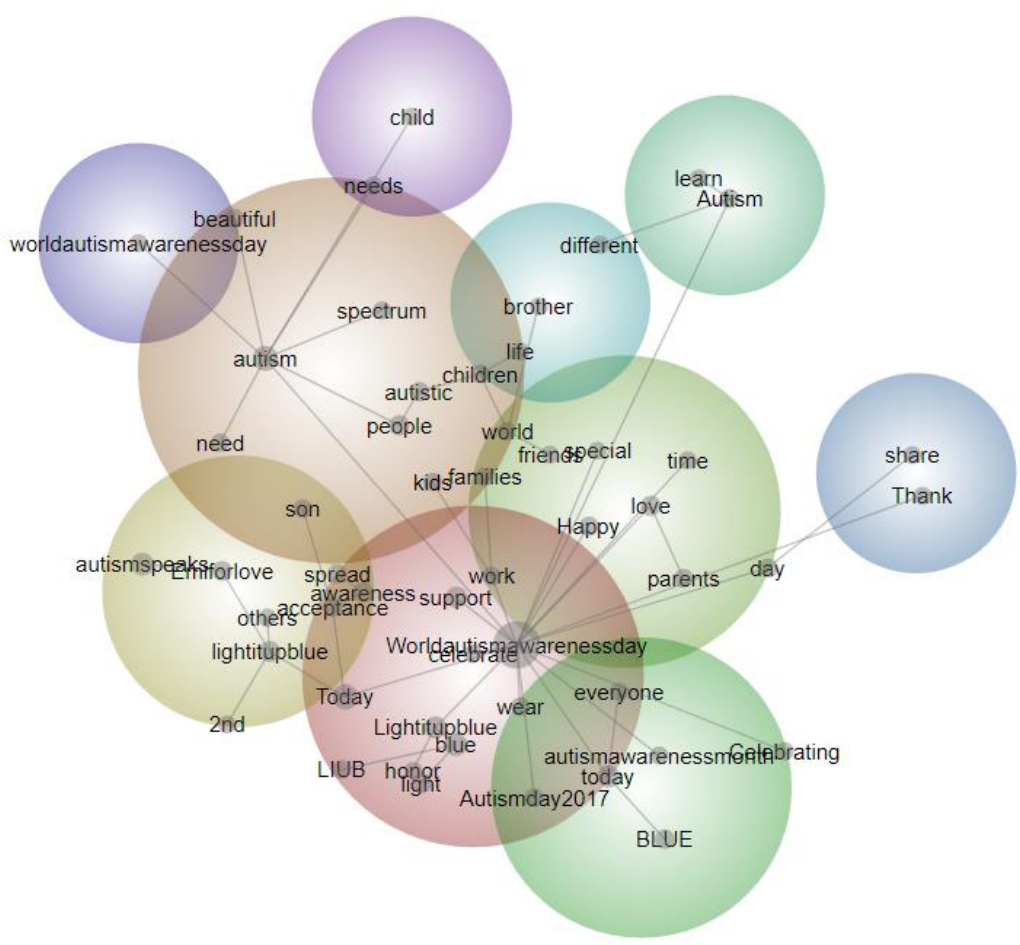

Figure 5. Global tweets 
When the contents of the tweets posted globally are examined, the topics of "difference" and "special," "light it up blue," "love/affection," and "prevalence," which are similar to the topics in Turkey, stand out in respect of raising awareness. When the contents of the global tweets are reviewed, it is understood that most of the tweeters have children with ASD. It is expected from them to tweet for their children on this special day. The theme "social acceptance," one of the topics shared by families, is observed to be addressed, especially in terms of the classroom environment and peers. In the tweets posted to raise awareness, another remarkable point is that families touch upon the "adulthood" and "acquiring a profession" topics.

Within the scope of informative tweets, it attracts attention that there are many "false facts and myths" about ASD known to be correct; therefore, "links were shared" regarding this issue. Among these posts, in the global sample, the institution "Autism Speaks," which provides various information and carries out activities on this issue, comes to the fore. This result is similar to the results of the influential user and tag analysis mentioned previously. Autism Speaks was also a prominent institution when influential institutions were reviewed within the results of the user and tag analysis. In informative posts, the "definition" and "characteristics" of ASD are frequently emphasized. Concerning the definition and characteristics of ASD, it is observed that information contents related to its complex nature, brain development which is different from normal progress, and differences in eye contact, speech, social communication and cognitive development are shared. These posts can be said to be consistent with the diagnostic criteria of ASD and characterized by its most basic features.

\section{Discussion, Conclusion and Suggestions}

In this study, which examined the activities performed on Twitter on April 2, the World Autism Awareness Day, in Turkey and globally, the cooperation and common statements of different institutions and organizations in both Turkish and global samples appear as extremely significant topics for the activities to be more effective and serve the purpose of raising awareness. Such awareness activities carried out particularly by ASD-related institutions on online social networks will enable reaching larger masses and thus, raising awareness further. However, in both samples, interinstitutional cooperation can be said to be a "sparse" network. In the Report of the Turkey Autism Assembly (2019), it was stated that the communication and cooperation of the relevant institutions were highly poor, especially in the domestic sense, and the interinstitutional cooperation should be strengthened. As known, interinstitutional cooperation and especially common posts can significantly accelerate the dissemination of information and innovations and assume an important role, enabling the information within the network to reach others in a short time. Thus, it can be asserted that there is a higher need for effective inter-institutional cooperation, which addresses all the segments of society, particularly on this meaningful day with regards to ASD awareness. In line with this, to create sensitivity on ASD in cooperation with the responsible and relevant institutions, they can prepare public service ads and short films using online social media or organize social activities or various campaign supports which will directly help families and individuals with ASD, who can express themselves, to make themselves heard. They can also hold webinars involving different domain experts and online interactive scientific sharing activities on ASD. In this respect, the "Tohum Autism Foundation," which aims to provide all the individuals interested in the subject with information about ASD and skills and carries out activities for ASD awareness, has been organizing various campaigns, activities and studies, in different years. For example, "the Research on Individuals' Perception of Autism in Turkey" was conducted by the Tohum Autism Foundation, with the support of GFK Turkey, in 15 provinces in 2015, and according to the study results, it was revealed that only 3 of every 10 individuals in Turkey heard of ASD, $7 \%$ knew about the symptoms of ASD, and only $19 \%$ of the participants had accurate information about its causes. The study, which was carried out using the face-to-face survey technique, revealed that women had higher awareness than men, $63 \%$ of the participants did not have anyone with ASD in their environments, and only $18 \%$ of those who heard of ASD thought ASD could be treated, and the main method used in the treatment was mostly hospital treatment (Rakap, 2017). The results of this study suggest, 
along with the results of other studies in the literature, that the knowledge and awareness level on ASD is generally quite low in our society. At this point, there is an urgent need for regular informative activities to raise awareness of ASD. The tweets from Turkey also support this idea. Although awareness tweets constitute the majority of the prominent tweets in Turkey, there are also tweets with informative content, although rarely. In this context, the emphasis put on "early diagnosis" can be evaluated as a pleasing situation because early diagnosis is the most important stage for the ASD risk (Guthrie et al., 2013; Vivanti et al., 2016). Early diagnosis is an extremely significant factor that helps the child and the family to draw a road map to plan and implement the child's education early and initiates this intervention. Awareness activities and inter-institutional cooperation, early diagnosis, the establishment of the treatmentintervention chain, development of family-oriented services, educational assessment, special education, development of support, education and rehabilitation services, employment, providing working life and social relief, and activities for participation in social life have been defined as the primary areas by the National Action Plan for Individuals with Autism Spectrum Disorder, the Ministry of Family and Social Policies (2016-2019) in Turkey. In line with the action plan, health professionals can be said to have significant responsibilities in increasing the ASD awareness level of the society and screening and monitoring for the early diagnosis of ASD.

When influential users, tags, and tweet contents were analyzed globally, the institution Autism Speaks came to the fore. As one of the leading institutions with a mission to provide the whole society, all the shareholders, especially including individuals with ASD and their families, with information on ASD awareness, Autism Speaks initiated awareness activities with its Light it up the blue campaign in 2014, and the statement' light it up blue' is a slogan that is one of the most repeated tweets worldwide. However, apart from these two institutions, many institutions carry out awareness activities such as seminars, speeches, informative or empathy or running activities on various media other than social media, although they do not come to the forefront on social media. Accordingly, it is hoped that awareness of ASD can be raised in a larger segment of society if institutions perform these activities, they plan on social media more often. The inclusion of individual nodes as well as corporate nodes in social media will be encouraging for participation independent of space and time. In this context, it is thought that ASD-related institutions and organizations can be among the intermediary institutions in the dissemination of information about the most popular available applications. This also emerges as an expected development in our technological era. Furthermore, it is considered that the inclusion of people who are renowned and accepted as role models by society and have a certain group of people following them in activities for raising ASD awareness, as in global activities, may positively affect increasing the widespread impact of awareness. However, the speed of the propagation of tweets is higher, which may pose some risks. For example, wrong information can be provided, such as the difficulty in understanding ASD, the possibility of confusing it with the diagnosis of other disability groups (Down syndrome, mental disability, etc.) or availability of no experience on ASD (Chansa-Kabali et al., 2019). Therefore, the content of the tweets posted may need to be checked by authorized and relevant institutions/people.

When the discourses in both samples are examined, topics such as differences, social acceptance and employment come to the forefront in addition to the definition and characteristics of ASD, prevalence and informative contents. Since ASD is a disorder characterized by deficiencies in social interaction and communication, it is expected from families of children with ASD to be worried about this issue. Many families who have children with ASD continuing their education face the rejection of their children in the social environment. In the relevant literature, many research findings are suggesting that an environment of social exclusion, social isolation, and pressure is created for individuals with ASD and their families worldwide, and therefore, children and their families have difficulty in adapting to society (Boyd et al., 2014; Divan et al., 2012; Ludlow et al., 2012; Marsack \& Perry, 2018). In the contents of the tweets posted, this is clearly mentioned. Compared to other disability groups, individuals with ASD have more difficulty in finding a job and acquiring a profession due to their social interaction and communication skills and 
repetitive-obsessive behaviours (Hayward et al., 2019; Hendricks, 2010; Henninger \& Taylor, 2013; Taylor $\&$ Seltzer, 2011). These results stated in the literature overlap with supportive tweets on finding a job and acquiring a profession in this study. The involvement of individuals with ASD who are slightly affected and have no additional diagnosis in a profession may help them overcome the difficulties in social communication and integrate into society through the social support offered to them. Thus, there is a higher need for promoting activities about work and employment.

When the prominent topics on ASD awareness other than the previously mentioned are examined both for Turkey and in the global sense, there are some points worth discussing. Firstly, early diagnosis and early education come to mind when ASD awareness is mentioned. However, as a result of the tweet and discourse analysis, no contents proving this fact were encountered globally, while there was a content touching upon it in Turkey. This can be explained as follows. Tweet contents were produced by families rather than experts. Secondly, it draws attention that families mostly preferred posting emotional tweets about love, special and different children and tweets about social acceptance and support. However, in the literature, one of the issues frequently addressed by families is the difficulties experienced in the diagnosis (Gupta, 2007; Moh \& Magiati, 2012; Pisula, 2011). Although links of doctor interviews were shared in two global tweets, early diagnosis and early education were not emphasized directly. In addition to early diagnosis, the deficiencies of children diagnosed with ASD can be reduced with systematic and continuous education (Brian et al., 2016; Schreibman et al., 2015). There is a need for experts experienced in ASD and relevant institutions to assume a more active role in sharing more contents emphasizing early diagnosis and early education on such an important day because there may be some families who are carrying the ASD risk but are not aware of the early symptoms or do not accept these differences. The awareness contents of the relevant, reliable institutions working directly on ASD can be motivating for families in terms of early diagnosis. Although many children diagnosed with ASD carry the risk of ASD before their second birthday, the study conducted by Maenner et al. (2020) suggests that the diagnosis of ASD is made in the 51st month on average across the world. Considering how important the first years of life are, as a period when brain development is the fastest (Schreibman et al., 2015; Zwaigenbaum et al., 2015), it should be remembered that delay in early diagnosis may result in many negative outcomes. This primarily leads to loss of time regarding the quality and intensity of education and prevents closing the gap between diagnosis and education. At this point, it can be said that relevant institutions should make more efforts to raise awareness of ASD on social media within the scope of the early diagnosis and early education theme. As another significant point, it is recommended not to limit the awareness activities performed in line with the significance of the month April and April 2 only to this month and day, but to increase the power of social awareness on ASD with organized and controlled activities via interinstitutional cooperation for 365 days.

This study has some limitations. The first one of these is the limitation of this study only to the activities held on April 2, 2017, on Twitter, which is a microblogging website. In this context, to support these data, tweets posted on social media can be examined, and comparative longitudinal studies can be conducted in the year range. Apart from Twitter, comparisons can be made on the data collected on different social platforms like Facebook. Social network analysis studies can be conducted over social media on the experiences and narrations of the families who have children with ASD. The second limitation is the inclusion of the tweets using the hashtags \#otizm [autism], \#2nisanotizmfarkindalıkgünü [April 2 Autism Awareness Day], \#autism [autism], and \#\#worldautismawarenessday in the study. In this context, to support or diversify the results of this study, studies in the mixed research design can be performed to use social network and content analyses by including tweets with different contents.

\section{References}

Aile ve Sosyal Politikalar Bakanlığ 1 [The Ministry of Family and Social Policies]. (2016). Otizm Spektrum Bozukluğu Olan Bireylere Yönelik Ulusal Eylem Planı (2016-2019) [National Action Plan for $\begin{array}{lllll}\text { Individuals } \quad \text { with } \quad \text { Autism } & \text { (2016-2019)]. }\end{array}$ 
http://www.sp.gov.tr/upload/xSPTemelBelge/files/5w4h6+otizm_eylem_plani_kitap_bakanli_ona ylanan.pdf

Al-Farsi, O. A., Al-Farsi, Y. M., Al-Sharbati, M. M., \& Al-Adawi, S. (2016). Stress, anxiety, and depression among parents of children with autism spectrum disorder in Oman: a case-control study. Neuropsychiatric Disease and Treatment, 12, 1943-1951. https://doi.org10.2147/NDT.S107103

Alsehemi, M. A., Abousaadah, M. M., Sairafi, R. A., \& Jan, M. M. (2017). Public awareness of autism spectrum disorder. Neurosciences, 22(3), 213-215. https://doi.org/10.17712/nsj.2017.3.20160525

American Psychiatric Association. (2013). Diagnostic and statistical manual of mental disorders (DSM5). 5 ed. American Psychiatric Association.

Berelson, B. (1952). Content analysis in communication research. Free Press.

Biber, K., Cankorur, H., Akçay, Z. N., \& Şumnulu, B. (2018). Çocukları okul öncesi eğitime devam eden annelere otizm spektrum bozukluğuna yönelik farkındalık eğitimi. Electronic Turkish Studies, 13(11), 345-362. http://dx.doi.org/10.7827/TurkishStudies.13556.

Bitsika, V., \& Sharpley, C. F. (2004). Stress, anxiety and depression among parents of children with autism spectrum disorder. Journal of Psychologists and Counsellors in Schools, 14(2), 151161. https://doi.org/10.1017/S1037291100002466

Bourgeron, T. (2016). Current knowledge on the genetics of autism and propositions for future research. Comptes Rendus Biologies, 339(7-8), 300-307. https://doi.org/10.1016/j.crvi.2016.05.004

Boyd, B. A., McCarty, C. H., \& Sethi, C. (2014). Families of children with autism: A synthesis of family routines literature. Journal of Occupational Science, 21(3), 322-333. https://doi.org/10.1080/14427591.2014.908816

Brian, J., Doyle-Thomas, K., Baribeau, D., \& Anagnostou, E. (2016). Novel mechanisms and treatment approaches in autism spectrum disorder. Discovery Medicine, 22(119), 47-54.

Centers for Disease Control and Prevention [CDC]. (2020). Community report on autism. https://www.cdc.gov/ncbddd/autism/addm-community-report/documents/addm-communityreport-2020-h.pdf

Chansa-Kabali, T., Nyoni, J., \& Mwanza, H. (2019). Awareness and Knowledge Associated with Autism Spectrum Disorders Among University Students in Zambia. Journal of Autism and Developmental Disorders, 49(9), 3571-3581. https://doi.org/10.1007/s10803-019-04044-7

Clauset, A., Newman, M. E., \& Moore, C. (2004). Finding community structure in very large networks. Physical Review E, 70(6), 066111. https://doi.org/10.1103/PhysRevE.70.066111

Creswell, J. W. (2012). Educational research: Planning, conducting, and evaluating quantitative and qualitative approaches to research. Merrill/Pearson Education.

Dillenburger, K., Jordan, J. A., McKerr, L., Lloyd, K., \& Schubotz, D. (2017). Autism awareness in children and young people: Surveys of two populations. Journal of Intellectual Disability Research, 61(8), 766-777. https://doi.org/10.1111/jir.12389

Divan, G., Vajaratkar, V., Desai, M. U., Strik-Lievers, L., \& Patel, V. (2012). Challenges, coping strategies, and unmet needs of families with a child with autism spectrum disorder in Goa, India. Autism Research, 5(3), 190-200. https://doi.org/10.1002/aur.1225

Elsabbagh, M., Divan, G., Koh, Y., Kim, Y. S., Kauchali, S., Marcín, C., Montiel-Nava, C., Patel, V., Paula, C. S., Wang, C., Yasamy, M. T., \& Fombonne, E. (2012). Global Prevalence of Autism and Other 
Pervasive Developmental Disorders: Global epidemiology of autism. Autism Research, 5(3), 160179. https://doi.org/10.1002/aur.239

Gupta, V. B. (2007). Comparison of parenting stress in different developmental disabilities. Journal of Developmental and Physical Disabilities, 19(4), 417-425. https://doi.org/10.1007/s10882-007$\underline{9060-\mathrm{X}}$

Gürsakal, N. (2009). Sosyal ağ analizi [Social network analysis]. Dora Yayıncılık.

Guthrie, W., Swineford, L. B., Nottke, C., \& Wetherby, A. M. (2013). Early diagnosis of autism spectrum disorder: stability and change in clinical diagnosis and symptom presentation. Journal of Child Psychology and Psychiatry, 54(5), 582-590. https://doi.org/10.1111/jcpp.12008

Hansen, D., Shneiderman, B., \& Smith, M. A. (2010). Analyzing social media networks with NodeXL: Insights from a connected world. Morgan Kaufmann.

Harel, D., \& Koren, Y. (2001). A Fast Multi-Scale method for drawing large graphs. In Graph Drawing: $8^{\text {th }}$ International Symposium, GD 2000, Colonial Williamsburg, VA, USA, September 20-23, 2000, Proceedings (No. 1984, p. 183). Springer Science \& Business Media.

Hayward, S. M., McVilly, K. R., \& Stokes, M. A. (2019). Autism and employment: What works. Research in Autism Spectrum Disorders, 60, 48-58. https://doi.org/10.1016/j.rasd.2019.01.006

Hendricks, D. (2010). Employment and adults with autism spectrum disorders: Challenges and strategies for success. Journal of Vocational Rehabilitation, 32(2), 125-134. https://doi.org/10.3233/JVR$\underline{2010-0502}$

Henninger, N. A., \& Taylor, J. L. (2013). Outcomes in adults with autism spectrum disorders: A historical perspective. Autism, 17(1), 103-116. https://doi.org/10.1177/1362361312441266

Huguet, G., Ey, E., \& Bourgeron, T. (2013). The genetic landscapes of autism spectrum disorders. Annual review of genomics and Human Genetics, 14, 191-213. https://doi.org/10.1146/annurev-genom091212-153431

Johnson, C. P., \& Myers, S. M. (2007). Identification and evaluation of children with autism spectrum disorders. Pediatrics, 120, 1183-1215. https://doi.org/10.1542/peds.2007-2361

Kinnear, S. H., Link, B. G., Ballan, M. S., \& Fischbach, R. L. (2016). Understanding the experience of stigma for parents of children with autism spectrum disorder and the role stigma plays in families' lives. Journal of Autism and Developmental Disorders, 46(3), 942-953. https://doi.org/10.1007/s10803-015-2637-9

Korkmaz, B. (2010). Otizm: Klinik ve nörobiyolojik özellikleri, erken tanı, tedavi ve bazı güncel gelişmeler. Türk Pediatri Arşivi, 45(2), 37-44.

Landa, R. J., \& Kalb, L. G. (2012). Long-term outcomes of toddlers with autism spectrum disorders exposed to short-term intervention. Pediatrics, 130(Supplement 2), S186-S190.

Lord, C., \& Bishop, S. L. (2015). Recent advances in autism research as reflected in DSM-5 criteria for autism spectrum disorder. Annual Review of Clinical Psychology, 11, 53-70. https://doi.org/10.1146/annurev-clinpsy-032814-112745

Ludlow, A., Skelly, C., \& Rohleder, P. (2012). Challenges faced by parents of children diagnosed with autism spectrum disorder. Journal of Health Psychology, 17(5), 702-711. https://doi.org/10.1177/1359105311422955

Maenner, M. J., Shaw, K. A., Baio, J., Washington, A., Patrick, M., DiRienzo, M., Christensen, D. L., Wiggins, L. D., Pettygrove, S., Andrews, J. G., Lopez, M., Hudson, A., Baroud, T., Schwenk, Y., 
White, T., Rosenberg, C. R., Lee, L., Harrington, R. A., Huston, M., ... Hall-Lande, J. (2020). Prevalence of autism spectrum disorder among children aged 8 years-autism and developmental disabilities monitoring network, 11 sites, United States, 2016. MMWR. Surveillance Summaries, 69(4),1-12. https://doi.org/10.15585/mmwr.ss6904a1

Marsack, C. N., \& Perry, T. E. (2018). Aging in place in every community: Social exclusion experiences of parents of adult children with autism spectrum disorder. Research on Aging, 40(6), 535-557. https://doi.org/10.1177/0164027517717044

Moh, T. A., \& Magiati, I. (2012). Factors associated with parental stress and satisfaction during the process of diagnosis of children with autism spectrum disorders. Research in Autism Spectrum Disorders, 6(1), 293-303. https://doi.org/10.1016/j.rasd.2011.05.011

Noterdaeme, M., \& Hutzelmeyer-Nickels, A. (2010). Early symptoms and recognition of pervasive developmental disorders in Germany. Autism, 14(6), 575-588. https://doi.org/10.1177/1362361310371951

Özçelik, A. A., Soysal, Ş., Arhan, E., Demir, E., Gücüyener, K., \& Serdaroğlu, A. (2015). Autism Spectrum Disorder Management Practices and Level of Knowledge Among General Pediatricians. Gazi Medical Journal, 26(4), 158-162.

Ozonoff, S., Iosif, A. M., Baguio, F., Cook, I. C., Hill, M. M., Hutman, T., Rogers, S. J., Rozga A., Sangha S., Sigman, M., Steinfeld, M. B., \& Young, G. S. (2010). A prospective study of the emergence of early behavioral signs of autism. Journal of the American Academy of Child \& Adolescent Psychiatry, 49(3), 256-266. https://doi.org/10.1016/j.jaac.2009.11.009

Pelletier, K., Brown, M., Brooks, D. C., McCormack, M., Reeves, J., Arbino, N., Bozkurt, A., Crawford, S., Czerniewicz, L., Gibson, R., Linder, K., Mason, J., \& Mondelli, V. (2021). 2021 EDUCAUSE Horizon Report Teaching and Learning Edition. EDUCAUSE. https://library.educause.edu/resources/2021/4/2021-educause-horizon-report-teaching-andlearning-edition

Pisula, E. (2011). Parenting stress in mothers and fathers of children with autism spectrum disorders. M. R. Mohammadi (Ed.), A Comprehensive book on autism spectrum disorders içinde (ss. 87-106), Rijeka, Croatia: INTECH Open Acsess Pulisher.

Rakap, S. (2017). Otizm spektum bozukluğu ve özel eğitim. Tohum Otizm Vakfi: Sivil Düşün AB Raporu.

Rakap, S., Balikci, S., Parlak-Rakap, A., \& Kalkan, S. (2016). An analysis of Turkish pre-service teachers' knowledge of autism spectrum disorder: Implications for teacher preparation programs. SAGE Open, 6, 1-11. https://doi.org/10.1177/2158244016668853

RaoSoft. (2020). Sample size calculator. http://www.raosoft.com/samplesize.html

Ronald, A., \& Hoekstra, R. A. (2011). Autism spectrum disorders and autistic traits: a decade of new twin studies. American Journal of Medical Genetics Part B: Neuropsychiatric Genetics, 156(3), 255274. https://doi.org/10.1002/ajmg.b.31159

Schreibman, L., Dawson, G., Stahmer, A. C., Landa, R., Rogers, S. J., McGee, G. G., Kasari, C., Ingersoll, B., Kaiser, A. P., Bruinsma, Y., McNerney, E., Wetherby, A., \& Halladay, A. (2015). Naturalistic developmental behavioral interventions: Empirically validated treatments for autism spectrum disorder. Journal of Autism and Developmental Disorder, 45(8), 2411-2428. https://doi.org/10.1007/s10803-015-2407-8

Smith, M., Rainie, L., Shneiderman, B., \& Himelboim, I. (2014). Mapping twitter topic networks: from polarized crowds to community clusters. http://www.pewinternet.org/2014/02/20/mapping-twittertopic-networks-from-polarized-crowds-to-community-clusters/ 
Taylor, J. L., \& Seltzer, M. M. (2011). Employment and post-secondary educational activities for young adults with autism spectrum disorders during the transition to adulthood. Journal of Autism and Developmental Disorders, 41(5), 566-574. https://doi.org/10.1007/s10803-010-1070-3

Türkiye Otizm Meclisi [Turkey Autism Assembly]. (2019). T.B.M.M. Down sendromu otizm ve Y.G.B. araştırma komisyonuna sunulmak üzere hazırlanan Türkiye Otizm Meclisi raporu. http://turkiyeotizmmeclisi.org/wpcontent/uploads/2019/10/TBMMSUNULANRAPOR.pdf

Vivanti, G., Dissanayake, C., \& Victorian ASELCC Team. (2016). Outcome for children receiving the Early Start Denver Model before and after 48 months. Journal of Autism and Developmental Disorders, 46(7), 2441-2449. https://doi.org/10.1007/s10803-016-2777-6

Wang, J., Zhou, X., Xia, W., Sun, C., Wu, L., \& Wang, J. (2012). Autism awareness and attitudes towards treatment in caregivers of children aged 3-6 years in Harbin, China. Social Psychiatry and Psychiatric Epidemiology, 47(8), 1301-1308. https://doi.org/10.1007/s00127-011-0438-9.

Wasserman, S., \& Galaskiewicz, J. (1994). Advances in social network analysis: Research in the social and behavioral sciences. Sage Publications.

Zwaigenbaum, L., Bauman, M. L., Fein, D., Pierce, K., Buie, T., Davis, P. A., Newschaffer, C., Robins, D. L., Wetherby, A., Choueiri, R., Kasari, C., Stone, W. L., Yirmiya, N., Estes, A., Hansen, R. L., McPartland, J. C., Natowicz, M. R., Carter, A., Granpeesheh, D., ... Wagner, S. (2015). Early screening of autism spectrum disorder: recommendations for practice and research. Pediatrics, 136 (Supplement 1), 41-S59. https://doi.org/10.1542/peds.2014-3667D 